\title{
EDitoriaL
}

\section{Novos sonhos, antigos pesadelos}

\section{Bárbara Nascente Kumagai ${ }^{1}$, Gustavo Rosa Gameiro²}

Como periódico científico, nosso objetivo primordial é levar à sociedade informações de alta relevância que se situam na fronteira do que o conhecimento humano foi até hoje capaz de desvendar. Publicamos ao longo de todo o ano o árduo trabalho de profissionais que se dedicam a atualizar nossas verdades e nossas condutas dentro da medicina, visando ao melhor desfecho possível em todos os casos. Nesta edição, especialmente dedicada à Obstetrícia e Ginecologia, não será diferente: traremos o que há de mais recente nos conceitos da área. Esbarramos atualmente, contudo, em um antigo entrave que, a despeito de todo o já consolidado conhecimento, retornou aos hospitais para mostrar ao Brasil que um ínfimo momento de descuido pode reviver antigos pesadelos que acreditamos por um segundo termos deixado para trás - revivemos nas maternidades as sequelas da transmissão vertical da sífilis.

Em tempos de empoderamento, o que fora percebido há algum tempo é que as novas gerações cada vez mais detêm conhecimento sobre as patologias e, infelizmente, cada vez menos as temem. Não há desfecho menos aterrorizante: dados da Pense (Pesquisa Nacional de Saúde do Escolar) de 2015 mostraram que apenas $65,6 \%$ dos adolescentes de 16 a 17 anos com vida sexual ativa haviam usado preservativo na última relação sexual ${ }^{1}$. É de se esperar que nesse ambiente a dispersão da bactéria seja bastante fácil. Segundo o Ministério da Saúde, em 2016 foram notificados 20.474 casos de sífilis congênita. Apesar de termos que considerar que houve, também segundo o Ministério, um aumento na taxa de detecção da doença, ainda é de se preocupar que a transmissão vertical de uma doença tão antiga ainda seja responvável atualmente por esse assombroso número de $\operatorname{casos}^{2,3}$.

Mais assombroso ainda é assistir a tal recrudescimento e lembrar que há disponível no Sistema Único de Saúde (SUS) testes rápidos que são incluídos no pré-natal e que preveniriam a transmissão vertical da bactéria. Infelizmente, ainda podemos notar casos de gestantes acometidas pela sífilis que não realizam adequadamente os testes. Não há como não notar também a existência de situações em que as pacientes são

1. Acadêmica da Faculdade de Medicina da Universidade de São Paulo. Editora-chefe da Revista de Medicina (Gestão 2018).

2. Acadêmico da Faculdade de Medicina da Universidade de São Paulo. Editor-chefe sênior da Revista de Medicina (Gestão 2018). 
testadas, porém não conseguem tratar a doença devido à falta de medicamento. O desabastecimento mundial de penicilina, que atualmente é produzida por poucas empresas ao redor do globo, é resultado principalmente de o medicamento ser barato, gerando pouco lucro para as empresas que o produz. Desse modo, a doença que em 2016 foi considerada epidemia pelo então Ministro da Saúde Ricardo Barros acaba encontrando na ausência da procura do pré-natal pelas gestantes e na dificuldade de encontrar tratamento mais vias de entrada para as maternidades.

A sífilis é sem dúvidas uma enfermidade antiga, cujo conhecimento sobre a qual possuímos já está, em sua maior parte, devidamente fundamentado. Os novos tempos, entretanto, trazem uma realidade que nos empurra novamente para uma fronteira do conhecimento: como fazer com que a população retome o hábito de se utilizar preservativos? Como aumentar a adesão de todos para a feitura do teste? Como fornecer às gestantes maior acesso e qualidade do pré-natal e à toda a população o tratamento adequado? As próximas gerações a ocuparem nossas maternidades, sem dúvidas, precisam de celeridade na descoberta de tais respostas.

Fica aqui a esperança deste corpo editorial de que, em vez de ver ressurgir problemas passados, cada vez mais a sociedade possa se ocupar com pouco desvendadas adversidades. Estaremos prontos e ávidos para continuar publicando neste periódico centenário o que há de mais atual e relevante na medicina.

Uma ótima leitura a todos!

\section{Referências}

1. IBGE - Instituto Brasileiro de Geografia e Estatística. Pesquisa Nacional de Saúde do Escolar 2015. Disponível em: https:/ww2.ibge.gov.br/home/estatistica/populacao/pense/2015/default.shtm.

2. Brasil. Ministério da Saúde. Departamento de Vigilância, Prevenção e Controle das IST. Secretaria de Vigilância em Saúde. Sífilis 2017. Bol Epidemiol. 2017;48(36):1-52. Disponível em: http://portalarquivos.saude.gov.br/images/ pdf/2017/novembro/13/BE-2017-038-Boletim-Sifilis-11-2017-publicacao-.pdf.

3. Ministro da Saúde admite que Brasil vive uma epidemia de sífilis. Disponível em: https://istoe.com.br/ministro-da-saudeadmite-que-brasil-vive-uma-epidemia-de-sifilis/. 